\title{
ANÁLISE ERGONÔMICA DO TRABALHO DE UMA PROFESSORA DA EDUCAÇÃO ESPECIAL
}

\section{AN ERGONOMIC WORK ANALYSIS OF A SPECIAL EDUCATION TEACHER}

\author{
Crislaine Gruber $^{1}, \mathrm{M}^{\mathrm{a}}$ \\ Marina Bernardes ${ }^{2}$, B.el \\ Tálita Bitencourt Pereira ${ }^{3}$, B.el \\ Lizandra Garcia Lupi Vergara ${ }^{4}$, D.ra \\ Leila Amaral Gontijo ${ }^{5}$, D.ra \\ (1) Instituto Federal de Santa Catarina e Universidade Federal de Santa Catarina \\ e-mail: crislaine.gruber@ifsc.edu.br \\ (2) Universidade Federal de Santa Catarina \\ e-mail: arq.marinabernardes@gmail.com \\ (3) Universidade Federal de Santa Catarina \\ e-mail: talitabit.pereira@gmail.com \\ (4) Universidade Federal de Santa Catarina \\ e-mail: l.vergara@ufsc.br \\ (5) Universidade Federal de Santa Catarina \\ e-mail: leila.gontijo@ufsc.br
}

Trabalho docente, Ergonomia, AET

Este trabalho apresenta uma Análise Ergonômica do Trabalho de uma professora da educação especial. Foram realizados: registros fotográficos; entrevistas; acompanhamento das atividades; medição do deslocamento; avaliação da carga de trabalho por meio do NASA TLX. Recomendações ergonômicas relacionadas à organização do trabalho e ao espaço físico foram sugeridas com base na análise.

\section{Teaching, Ergonomics, Ergonomic Work Analysis}

This paper presents an Ergonomic Work Analysis of a special education teacher. We made photographic records; interviews; monitoring activities; displacement measurement; workload assessment through NASA TLX. Ergonomic recommendations related to work organization and physical space were suggested based on the analysis. 


\section{$16^{\circ}$ \\ ERGODESIGN USIHC CINAHPA}

\section{Introdução}

A ação ergonômica tem como objetivo principal transformar o trabalho de forma a contribuir para a concepção de situações de trabalho que não alterem a saúde dos operadores e o alcance dos objetivos econômicos determinados pela empresa (GUÉRIN et al, 2001). A abordagem adotada neste trabalho é a Análise Ergonômica do Trabalho (AET), na qual a atividade (trabalho real) ocupa lugar central e é diferenciada do trabalho prescrito, chamado de tarefa (FERREIRA, 2015). O artigo apresenta a AET de uma professora da Educação Especial, modalidade de educação escolar oferecida preferencialmente na rede regular de ensino, para educandos com deficiência, transtornos globais do desenvolvimento e altas habilidades ou superdotação (BRASIL, 1996).

Alves (2015) afirma que "o diálogo com as ciências do trabalho pode aportar aspectos teóricos e metodológicos importantes para a compreensão do trabalho docente." Para ele, a ergonomia da atividade possibilita explorar aspectos negligenciados nas pesquisas em educação.

\section{Procedimentos metodológicos}

A AET foi utilizada neste trabalho, subsidiada pelos seguintes procedimentos metodológicos: entrevistas semiestruturadas com a professora e com a Coordenadora à qual ela está vinculada; acompanhamento de dois dias de trabalho, no Colégio; registros (textuais e fotográficos) das situações vivenciadas pela professora na atividade.

A análise do trabalho é a análise de um conjunto: tarefa, como resultado antecipado fixado em condições determinadas; atividade de trabalho, como realização da tarefa; e trabalho, como unidade da atividade de trabalho, das condições reais e dos resultados efetivos dessa atividade (GUÉRIN et al, 2001). Para análise da tarefa, foram coletados documentos do Colégio disponíveis na internet, os quais tratam do trabalho dos profissionais da educação especial. Para análise da atividade, foi aplicado o instrumento NASA TLX de avaliação da carga de trabalho. Também foi realizada a contagem de passos da $16^{\circ}$ Ergodesign - Congresso Internacional de Ergonomia e Usabilidade de Interfaces Humano Tecnológica: Produto, Informações Ambientes Construídos e Transporte

$16^{\circ}$ USIHC - Congresso Internacional de Ergonomia e Usabilidade de Interfaces Humano Computador

CINAHPA | 2017 - Congresso Internacional de Ambientes Hipermídia para Aprendizagem. professora por meio de um aplicativo de celular chamado Pedômetro, a fim de determinar aproximadamente qual distância ela percorre em uma tarde de trabalho. O aplicativo, instalado em um telefone celular, conta o número de passos dados pela pessoa que carrega o aparelho.

O instrumento NASA TLX tem seis dimensões: exigência mental, exigência temporal, exigência física, esforço, desempenho e nível de frustração. A avaliação foi feita no final de uma manhã de trabalho na qual a professora participou de uma reunião de professores e ao final de uma tarde de trabalho, na qual a professora esteve em sala de aula com os estudantes.

O instrumento foi aplicado nas seguintes etapas: 1) apresentação das definições das seis dimensões à participante (Figura 1);2) avaliação da atividade de trabalho que a participante realizou por meio de escalas não numéricas (Figura 2). A participante marca nas escalas como ela se sente após realizar a atividade; 3) apresentação de 15 pares de dimensões (exemplo: esforço ou desempenho), nos quais a participante seleciona a dimensão que tem maior importância em relação à carga de trabalho da atividade que está sendo avaliada, sempre considerando cada par isoladamente. Quanto mais vezes a participante selecionar uma dimensão, maior peso esta terá na avaliação da sua carga de trabalho; 4) análise dos dados: os valores marcados pela participante em cada uma das escalas não numéricas são multiplicados por 5; são contadas as vezes que cada dimensão foi selecionada nos pares; faz-se a multiplicação desses dois valores; para obter a taxa global da carga de trabalho, somam-se os valores resultantes em cada dimensão e divide-se por 15 .

Em relação aos aspectos éticos, a Coordenadoria de Pesquisa e Extensão do Colégio autorizou as pesquisadoras a realizarem o trabalho junto à professora selecionada.

\section{Resultados e discussões}

\subsection{Análise da demanda}

Para definir a problemática inicial, foi realizada
Realização:

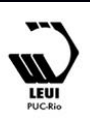




\section{$16^{\circ}$ \\ ERGODESIGN USIHC CINAHPA}

uma entrevista semiestruturada com a professora, para conhecer seu ambiente de trabalho e seu ponto de vista em relação ao próprio trabalho.

Posteriormente, foi realizada uma entrevista semiestruturada com a Coordenadora de Apoio Administrativo ao Ensino Fundamental - Anos Finais, a fim de conhecer o seu ponto de vista sobre o trabalho da professora. Com base nesse levantamento, foi definida a problemática inicial da AET: frequentemente, a professora de Educação Especial não tem tempo hábil para preparar o material especial a partir do material utilizado na turma regular; e, o espaço físico disponível para a professora realizar seu trabalho apresenta problemas, tais como: as salas são distantes umas das outras e em diferentes andares; a sala de Atendimento Educacional Especializado é pequena e tem agenda disputada entre os professores da Educação Especial.

\begin{tabular}{|c|c|c|}
\hline \multicolumn{3}{|c|}{ DEFINIÇõES DAS ESCALAS DE AVALIAÇÃO } \\
\hline Título & Endpoints & Descrições \\
\hline EXIGÊNCIA MENTAL & Baixa/Alta & $\begin{array}{l}\text { Quanta atividade mental e de percepção foi } \\
\text { exigida (por exemplo: pensar, decidir, calcular, } \\
\text { lembrar, olhar, pesquisar, etc.)? A tarefa foi } \\
\text { fácil ou exigente, simples ou complexa, rigorosa } \\
\text { ou flexível? }\end{array}$ \\
\hline EXIGÊNCIA FÍSICA & Baixa/Alta & $\begin{array}{l}\text { Quanta atividade física foi exigida (por exemplo: } \\
\text { empurrar, puxar, virar, controlar, ativar, etc.)? A } \\
\text { tarefa foi fácil ou exigente, lenta ou ativa, } \\
\text { suave ou extenuante, sossegada ou trabalhosa? }\end{array}$ \\
\hline $\begin{array}{l}\text { EXIGÊNCIA } \\
\text { TEMPORAL }\end{array}$ & Baixa/Alta & $\begin{array}{l}\text { Quanta pressão de tempo você sentiu devido ao } \\
\text { ritmo em que as tarefas ou os elementos da } \\
\text { tarefa ocorreram? O ritmo foi lento e vagaroso } \\
\text { ou rápido e frenético? }\end{array}$ \\
\hline DESEMPENHO & Bom/Ruim & $\begin{array}{l}\text { Quanto sucesso você acha que obteve em } \\
\text { realizar os objetivos da tarefa definida pelo } \\
\text { pesquisador (ou por você mesma)? Quão } \\
\text { satisfeita você ficou com seu desempenho em } \\
\text { realizar esses objetivos? }\end{array}$ \\
\hline ESFORÇO & Baixo/Alto & $\begin{array}{l}\text { Quão duro você teve que trabalhar } \\
\text { (mentalmente e fisicamente) para alcançar o } \\
\text { seu nível de desempenho? }\end{array}$ \\
\hline $\begin{array}{l}\text { NÍVEL DE } \\
\text { FRUSTRAÇÃo }\end{array}$ & Baixo/Alto & $\begin{array}{l}\text { Quão insegura, desanimada, irritada, estressada } \\
\text { e aborrecida versus segura, satisfeita, contente, } \\
\text { relaxada e complacente você se sentiu durante } \\
\text { a tarefa? }\end{array}$ \\
\hline
\end{tabular}

Figura 1: Definições das seis dimensões do NASA TLX. Fonte: traduzido de NASA (1986).

\subsection{Análise da tarefa}

\subsubsection{Pessoas}

A professora tem 30 anos de idade, é graduada em $16^{\circ}$ Ergodesign - Congresso Internacional de Ergonomia e Usabilidade de Interfaces Humano Tecnológica: Produto, Informações Ambientes Construídos e Transporte

$16^{\circ}$ USIHC - Congresso Internacional de Ergonomia e Usabilidade de Interfaces Humano Computador

CINAHPA | 2017 - Congresso Internacional de Ambientes Hipermídia para Aprendizagem.
Pedagogia e tem mestrado em Educação. Antes de ingressar no Colégio atual, em 2014, atuou como docente na educação básica, na educação especial e em cursos de graduação. A equipe de Educação Especial do Colégio é composta por 14 professores de Educação Especial, 2 professores de Libras e 3 técnicos administrativos. Esses profissionais compõem uma equipe multidisciplinar, juntamente com profissionais de saúde, a qual foi contratada em 2014 devido a uma ação judicial movida pelos pais de alunos.

Além da equipe multidisciplinar, a professora trabalha diretamente, em regime de co-docência, com os professores das diferentes disciplinas: História, Português, Matemática, etc. A professora tem o auxílio de dois bolsistas, estudantes de cursos de graduação, em seu trabalho. Esses bolsistas são solicitados pela própria professora conforme a necessidade e demanda de trabalho, e trabalham 16 horas semanais. A orientação aos bolsistas é feita pela professora.

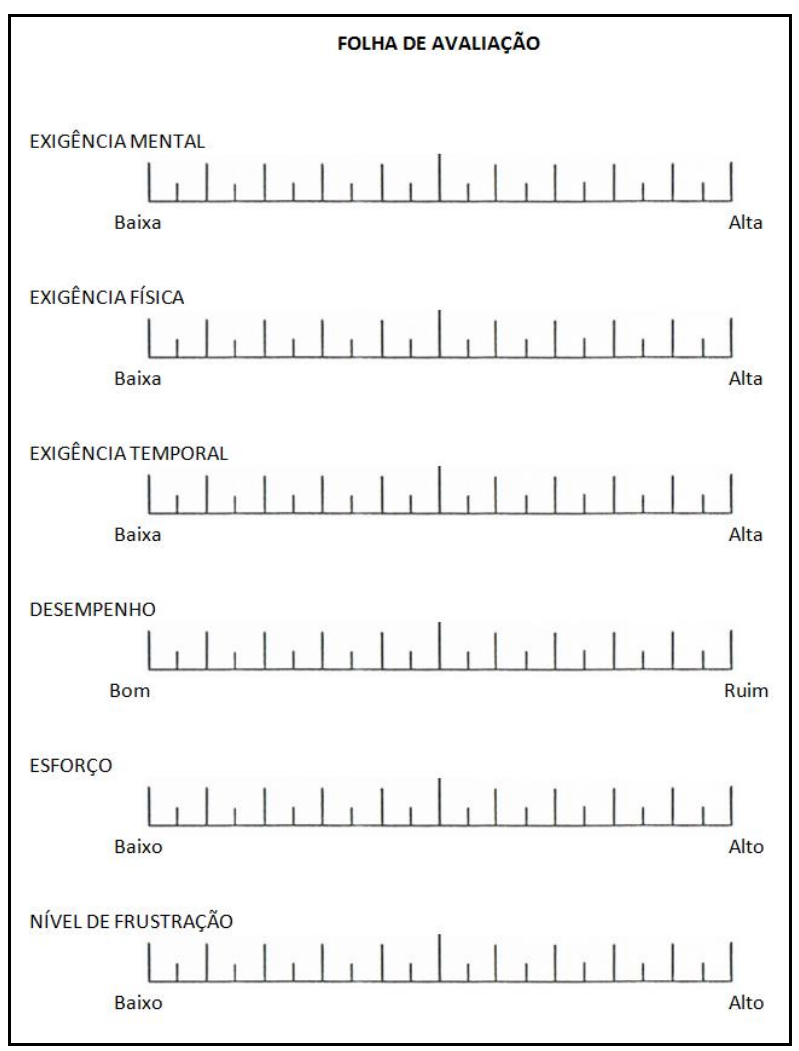

Figura 2: Escala das seis dimensões. Fonte: traduzido de NASA (1986).
Realização:
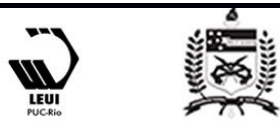


\section{$16^{\circ}$ \\ ERGODESIGN USIHC CINAHPA}

A professora pertence a vários coletivos, conforme apresentado por Alves (2015, p.15), o dos professores de uma rede de ensino, de uma escola, de um turno da escola, de um segmento da Educação Básica, de um corpo disciplinar específico. "Tais coletivos constituem formas de fazer e proceder, sedimentam as identidades profissionais e formas de aproximação ou distanciamento entre eles."

\subsubsection{Objetivos do trabalho da professora}

O Colégio tem uma Proposta Pedagógica de Inclusão Educacional, de acesso público, na qual são apresentadas as ações das professoras de Educação Especial. São elas:

- Realizar o ensino colaborativo de co-docência com o aluno em sala de aula ou em outros espaços em que sejam desenvolvidas as práticas pedagógicas, nas turmas dos anos finais e ensino médio, onde houver estudantes com deficiências, transtornos, altas habilidades/superdotação, cujas necessidades específicas justifiquem a presença de professor da Educação Especial.

- Participar dos projetos interdisciplinares desenvolvidos pelos professores da turma que conta com o trabalho de co-docência ou ensino colaborativo de co-docência, acompanhando e possibilitando ao aluno com deficiências, transtornos, altas habilidades/superdotação participar dos trabalhos de pesquisa desenvolvidos, bem como das saídas de campo ou viagens de estudo quando houver.

- Desenvolver Tecnologias Assistivas e materiais adaptados às necessidades dos alunos.

- Atuar em sala multifuncional, realizando Atendimento Educacional Especializado (AEE) no contra turno das aulas.

- Colaborar na elaboração de cursos para a comunidade escolar, em articulação com os demais profissionais do NAE.

- Organizar o planejamento de suas atividades com os demais professores, sendo que quando necessário, em conjunto com as pedagogas da $16^{\circ}$ Ergodesign - Congresso Internacional de Ergonomia e Usabilidade de Interfaces Humano Tecnológica: Produto, Informações Ambientes Construídos e Transporte

$16^{\circ}$ USIHC - Congresso Internacional de Ergonomia e Usabilidade de Interfaces Humano Computador

CINAHPA | 2017 - Congresso Internacional de Ambientes Hipermídia para Aprendizagem.
Educação Especial.

- Compartilhar a responsabilidade pelas atividades de vida autônoma dos alunos com deficiências, transtornos, altas habilidades/superdotação.

- Participar dos conselhos de classe, das reuniões de série, reuniões de pais das turmas, onde houver alunos por ele acompanhados.

- Participar dos processos de avaliação, auxiliando os professores no que se refere às especificidades dos alunos que apresentam deficiências, transtornos, altas habilidades/superdotação.

- Colaborar na orientação aos bolsistas que atuam em turmas onde as profissionais atuem em regime de co-docência.

Em relação à co-docência, a Coordenadora de Apoio Administrativo do Ensino Fundamental Anos Finais compreende que a professora da Educação Especial "faz um link entre o aluno especial e as disciplinas". Ela ressalta que a codocência "alivia" o trabalho dos professores das disciplinas; "cria um outro olhar nos professores das outras disciplinas"; o aluno "dá um salto muito grande" quando conta com esse regime. A orientação que a professora dá às famílias dos estudantes com deficiência ocorre diariamente, antes do início da aula ou ao final da aula.

Além das ações apresentadas na Proposta Pedagógica de Inclusão Educacional, o Plano de Ensino do $9^{\circ}$ ano do Colégio, ano 2016, apresenta objetivos da Educação Especial, sendo o principal: "possibilitar ao estudante público-alvo da Educação Especial acessibilidade ao currículo comum, bem como ampliação e domínio dos conhecimentos necessários para o seu desenvolvimento em todas as dimensões: cognitiva, afetiva, social, moral, física e estética, por meio de práticas pedagógicas que valorizem as diferenças dos sujeitos e do trabalho colaborativo com o grupo no qual o estudante está inserido". Esse Plano de Ensino apresenta, ainda, 11 objetivos específicos, conteúdo programático, metodologia, instrumentos de avaliação e Plano de Atendimento Individualizado. Em relação a este 


\section{$16^{\circ}$ \\ ERGODESIGN USIHC CINAHPA}

Plano, a professora deve elaborar um relatório anual do Atendimento Educacional Especializado (AEE) oferecido ao estudante.

As metas do trabalho da professora são definidas em função do que é significativo para cada estudante, pois depende muito de cada indivíduo. Essas metas, ou objetivos de aprendizagem, são definidos pela professora juntamente com os professores das disciplinas específicas.

\subsubsection{Ferramentas}

Para Alves (2015, p.16), as ferramentas estão a serviço das técnicas de ensino e são modificadas pelos professores para ganhar eficácia. "Selecionase e enfatiza-se partes do livro didático, complementa-se com extratos de uma matéria jornalística atual, prepara-se uma lista de exercícios no computador, compõe-se, refaz-se etc. $\mathrm{O}$ trabalho do professor sobre as ferramentas permite torná-las instrumentos para a ação, via para a instituição do meio de trabalho.”

A professora utiliza as seguintes ferramentas: tablet ou notebook com tela sensível ao toque, para realizar atividades com o aluno com deficiência múltipla, por exemplo; celular, para gravar vídeos dos alunos realizando atividades, comunicar-se com os bolsistas, etc.; computador, como apoio no AEE e para preparar materiais na Sala de Educação Especial; equipamentos de tecnologia assistiva, para atender os alunos com limitações físicas ou cognitivas: mouse adaptado, jogos e brinquedos, tesoura adaptada, dispositivos de comunicação alternativa, Tobii, GoTalk; impressoras.

\subsubsection{Entradas e saídas}

O ingresso dos alunos com deficiências ocorre por meio de sorteio de vagas, sendo que está prevista uma cota de $5 \%$ do número de alunos por série. $\mathrm{O}$ Colégio faz uma pré-análise dos alunos com deficiência para organizar o trabalho das professoras e definir por quais alunos cada professora será responsável.

A professora atende diretamente dois alunos do $9^{\circ}$ ano. Um com 15 anos de idade, que tem leve deficiência intelectual, atraso significativo na $16^{\circ}$ Ergodesign - Congresso Internacional de Ergonomia e Usabilidade de Interfaces Humano Tecnológica: Produto, Informações Ambientes Construídos e Transporte

$16^{\circ}$ USIHC - Congresso Internacional de Ergonomia e Usabilidade de Interfaces Humano Computador

CINAHPA | 2017 - Congresso Internacional de Ambientes Hipermídia para Aprendizagem.

linguagem, deficiência física devida a uma paralisia cerebral e a coordenação motora comprometida. A deficiência desse aluno é mais física do que intelectual. Ela atende também outra aluna do $9^{\circ}$ ano, que tem deficiência visual e cognitiva. Além desses dois alunos, existem outros alunos com necessidades especiais na turma do $9^{\circ}$ ano que são atendidos pela professora durante as aulas, quando há necessidade.

Uma das principais entradas do trabalho da professora de Educação Especial é o material utilizado pelos professores das disciplinas do $9^{\circ}$ ano. Esses materiais são adaptados pela professora para os alunos da Educação Especial de acordo com as limitações de cada um deles. Então, por exemplo, se o aluno tem baixa visão, a professora adapta o tamanho da fonte do material.

\subsubsection{Informações}

As informações relativas ao trabalho da professora de Educação Especial estão na Proposta Pedagógica de Inclusão Educacional, elaborada por uma comissão. A professora considera que essa Proposta está ainda em construção, que estará sempre em reformulação. Além da Proposta, têmse os Planos de Ensino anuais relacionados ao trabalho desenvolvido pelas professoras de Educação Especial em cada uma das séries.

Alves (2015, p.15) afirma que, na educação escolar, os prescritos são dispersos em várias instâncias (legislação educacional, disposições das secretarias de educação, das escolas, etc.). "O ensino, por sua natureza, acomoda prescrições dispersas e vagas quando em comparação com outros campos profissionais em que as prescrições podem ser muito precisas. Disso resulta que as escolas e seus docentes têm importante papel na interpretação e na definição das prescrições."

\subsubsection{Meio ambiente}

O Colégio é composto por diversos prédios e a professora costuma utilizar salas localizadas em diferentes partes dele (Figura 3). A Sala do AEE localiza-se no andar térreo, sendo acessível por uma rampa. A sala de aula do $9^{\circ}$ ano está no $1^{\circ}$
Realização:
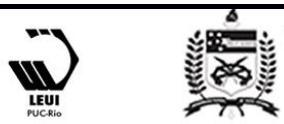


\section{$16^{\circ}$ \\ ERGODESIGN USIHC CINAHPA}

$16^{\circ}$ Ergodesign - Congresso Internacional de Ergonomia e Usabilidade de Interfaces Humano Tecnológica: Produto, Informações Ambientes Construídos e Transporte

$16^{\circ}$ USIHC - Congresso Internacional de Ergonomia e Usabilidade de Interfaces Humano Computador

CINAHPA | 2017 - Congresso Internacional de Ambientes Hipermídia para Aprendizagem. andar do prédio e também tem acesso por meio de rampas. A Sala de Educação Especial, utilizada pelas professoras da Educação Especial, localiza-se no $2^{\circ}$ andar do prédio, e o acesso a ela se dá por meio de escadas. O galpão, no qual estão equipamentos e espaços utilizados pela professora, como a impressora colorida, os dispositivos de Tecnologia Assistiva, o espaço do projeto Pés na Estrada, localiza-se anexo ao prédio principal do Colégio, no andar térreo. A sala da Inspetoria, onde fica a máquina de xerox e a impressão em preto e branco, fica no primeiro andar, ao lado da rampa de acesso e bem próxima a sala do $9^{\circ}$ ano.

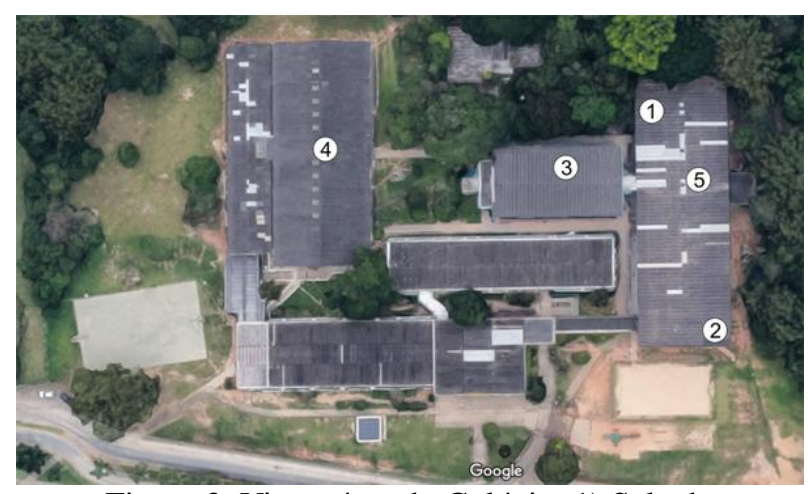

Figura 3: Vista aérea do Colégio: 1) Sala do

Atendimento Educacional Especializado; 2) Sala de aula do $9^{\circ}$ ano; 3) Sala de Educação Especial; 4) Galpão onde estão localizados os dispositivos de tecnologia assistiva, a impressora colorida, dentre outros equipamentos e espaços utilizados pela professora; 5) Sala da inspetoria. Fonte: autoras, a partir de Google Maps, 2016.

A sala do AEE possui recursos multimeios e de tecnologia assistiva e está dividida em dois espaços: um com mesa e cadeiras e outro com o armário de materiais (Figura 4). As professoras devem reservar com antecedência a sala. A professora em estudo possui a chave desta sala. A sala de aula do $9^{\circ}$ ano abriga: cerca de 40 estudantes, dispostos em fileiras de carteiras; o professor da disciplina, em sua mesa, à frente; a professora da Educação Especial e seus bolsistas, que costumam sentar nas mesmas carteiras utilizadas pelos estudantes.

O Colégio realizará reformas de infraestrutura física a fim de tornar o prédio acessível para os alunos da Educação Especial, inclusive com a instalação de um elevador. Prevê-se que a reforma começará a ser feita no segundo semestre de 2016.

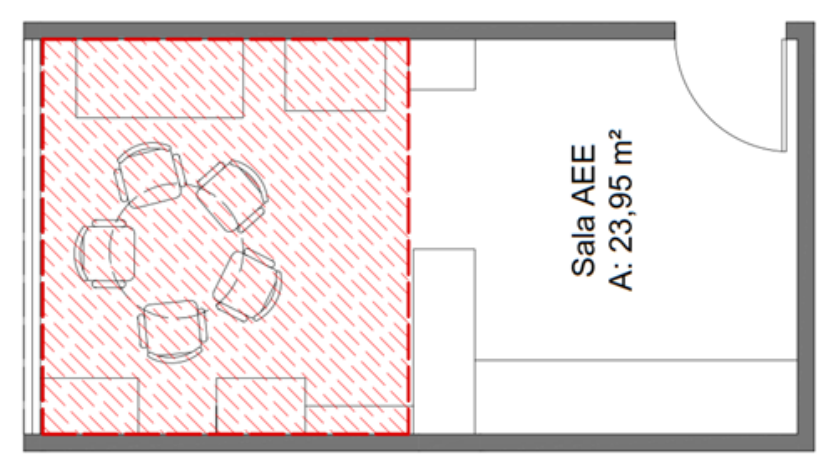

Figura 4: Planta baixa da sala do Atendimento Educacional Especializado. Fonte: autoras, 2016.

\subsubsection{Condições organizacionais}

O organograma do Colégio conta com três níveis: 1) Direção, 2) Vice-direção, 3) Coordenadorias: Apoio Administrativo ao Ensino Fundamental Anos Iniciais, Apoio Administrativo ao Ensino Fundamental - Anos Finais, Pesquisa e Extensão, Educação Física, Apoio Administrativo ao Ensino Médio, Estágios, Administração, Comunicação, Divulgação e Eventos. A professora de Educação Especial, por atuar com estudantes do $9^{\circ}$ ano do ensino fundamental, está ligada à Coordenadoria de Apoio Administrativo ao Ensino Fundamental Anos Finais (destaque na Figura 5).

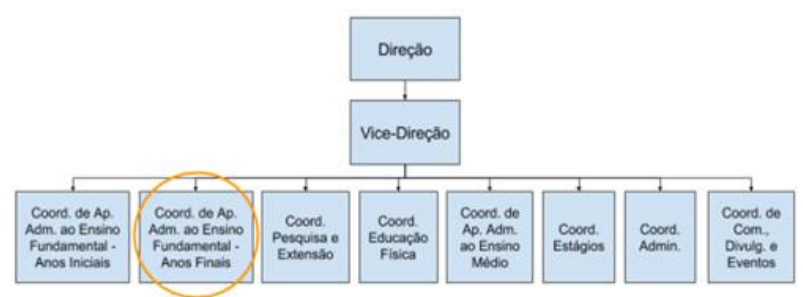

Figura 5: Organograma do Colégio. Fonte: adaptado do site do Colégio, 2016.

Para a Coord. de Apoio Administrativo ao Ensino Fundamental - Anos Finais, a professora de Educação Especial é uma professora como qualquer outra; sua diferença está em atender alunos específicos. Os compromissos da professora em relação à assiduidade, pontualidade, responsabilidade são iguais aos dos demais professores. A Coordenadora percebe a Educação Especial como uma disciplina, tal como Português, 


\section{$16^{\circ}$ \\ ERGODESIGN USIHC CINAHPA}

Matemática, etc. Quando tem algum problema com um aluno em sala de aula, a professora da Educação Especial procura por essa Coordenadora.

A professora trabalha 40 horas semanais, e tem dedicação exclusiva. Dessas 40 horas, 20 são voltadas para as atividades de ensino (18 horas em sala de aula e 2 horas no contra turno, realizando atendimento individualizado) e 20 são voltadas para atividades de pesquisa e extensão. A professora realiza Atendimento Educacional Especializado (AEE) no contra turno uma vez por semana para cada aluno. Esse horário é fixo para cada aluno, porém muitas vezes é difícil conciliar a agenda do aluno, pois ele realiza diversas atividades fora da escola no contra turno.

\subsection{Análise da atividade}

\subsubsection{Atendimento Educacional Especializado}

O Atendimento Educacional Especializado aconteceu em grupo. Estavam presentes na sala: duas professoras de Educação Especial, quatro alunos da Educação Especial e o professor de História (Figura 6). A professora observa em pé e grava parte do atendimento no próprio celular para preparar as próximas aulas em casa.

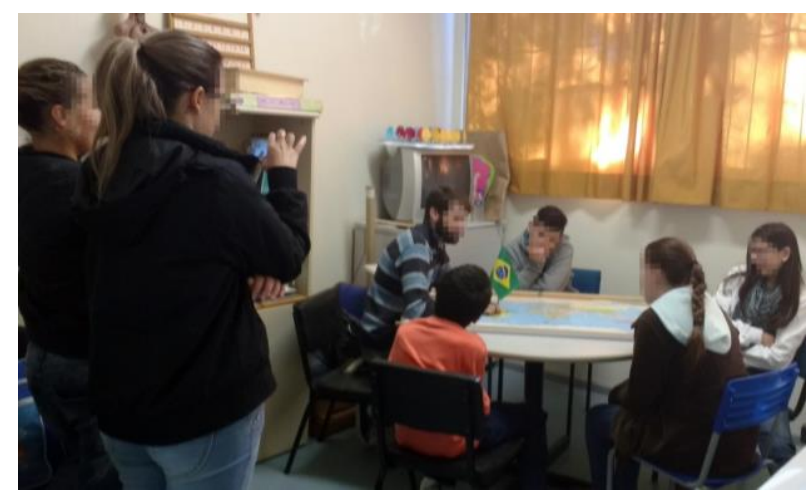

Figura 6: Atendimento Educacional Especializado com a participação de professoras da Educação Especial e professor de História. Fonte: autoras, 2016.

Durante o AEE não há cadeiras para todos se sentarem, a professora fica em pé durante 25 minutos e depois se apoia de forma improvisada em uma carteira (Figura 7). O professor de História deixa a sala quando termina o seu conteúdo, e pede uma atividade para os alunos da Educação $16^{\circ}$ Ergodesign - Congresso Internacional de Ergonomia e Usabilidade de Interfaces Humano Tecnológica: Produto, Informações Ambientes Construídos e Transporte

$16^{\circ}$ USIHC - Congresso Internacional de Ergonomia e Usabilidade de Interfaces Humano Computador

CINAHPA | 2017 - Congresso Internacional de Ambientes Hipermídia para Aprendizagem.

Especial. Ele solicita que a professora inicie a atividade com os alunos. A professora explica a atividade (Figura 8) e oferece revistas, folhas de papel, lápis, tesouras e cola para os alunos iniciarem a atividade. Todos esses materiais estavam disponíveis na sala do AEE.
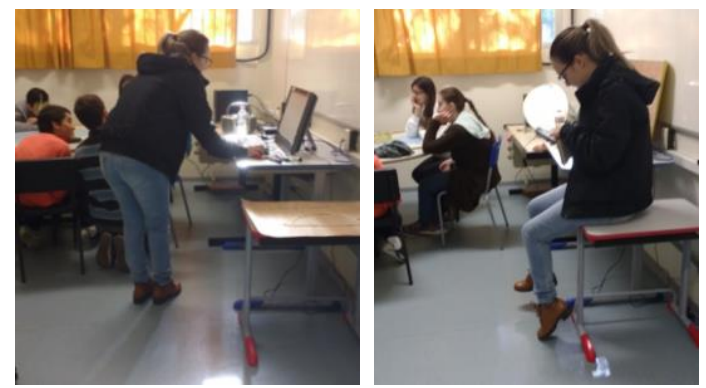

Figura 7: Atendimento Educacional Especializado: não há espaço para todos sentarem, a professora fica em pé durante 25 minutos e depois encosta em uma carteira. Fonte: autoras, 2016.

\subsubsection{Sala de aula}

A professora acompanha os alunos da Educação Especial na sala regular do $9^{\circ}$ ano. Ela se senta ao lado ou atrás de um dos alunos (Figura 9). A professora fica atenta à aula, aos seus alunos da educação especial e aos bolsistas. Ela não faz grandes intervenções na aula, essas intervenções são referentes a pedir silêncio para a turma ou dar alguma sugestão para o andamento da aula.

Na sala de aula, os estudantes da Educação Especial costumam sentar nas carteiras mais próximas ao quadro branco e a porta. A professora da Educação Especial e seus bolsistas costumam sentar atrás ou ao lado desses estudantes.

Assim que o professor da disciplina passa alguma atividade, a professora da Educação Especial inicia a flexibilização para os seus alunos. Ela utiliza o próprio notebook para isso, pois o da escola deve ser reservado com antecedência e utilizado durante um turno (Figura 10). A professora afirma que a sala onde estão os recursos é longe e que quando faz no seu notebook a atividade permanece salva nele e ela pode adaptá-la em casa mais facilmente.

Durante a aula regular, acontecem as orientações aos projetos de Iniciação Científica. A professora
Realização:
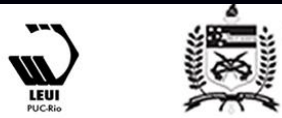


\section{$16^{\circ}$ \\ ERGODESIGN USIHC CINAHPA}

$16^{\circ}$ Ergodesign - Congresso Internacional de Ergonomia e Usabilidade de Interfaces Humano Tecnológica: Produto, Informações Ambientes Construídos e Transporte

$16^{\circ}$ USIHC - Congresso Internacional de Ergonomia e Usabilidade de Interfaces Humano Computador

CINAHPA | 2017 - Congresso Internacional de Ambientes Hipermídia para Aprendizagem. orienta quatro grupos; dois deles com da Educação Especial. A orientação ocorre uma vez por semana, durante 90 minutos, em diferentes salas.

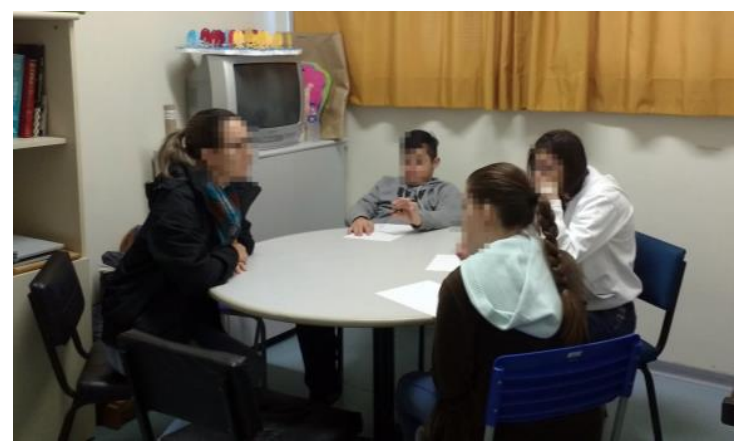

Figura 8: Atendimento Educacional Especializado: a professora orienta os alunos quanto à atividade. Fonte: autoras, 2016.
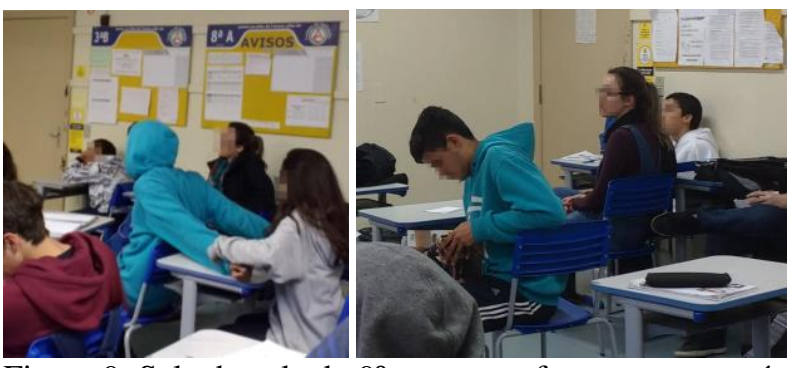

Figura 9: Sala de aula do $9^{\circ}$ ano: a professora senta atrás do estudante de Educação Especial (esquerda) e ao lado, no corredor entre as fileiras de carteiras (direita). Fonte: autoras, 2016.

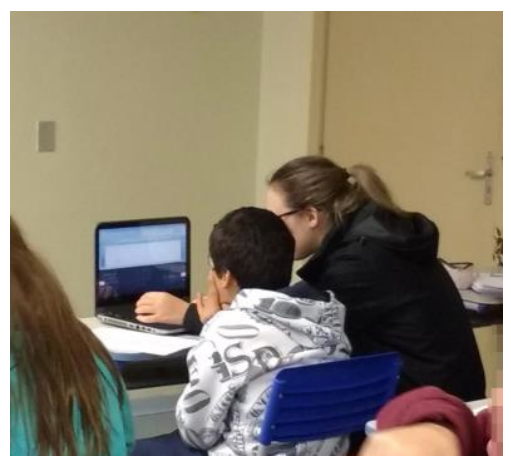

Figura 10: Professora utilizando seu notebook (com tela sensível ao toque) para atender o estudante na sala de aula do $9^{\circ}$ ano. Fonte: autoras, 2016.

\subsubsection{Atividades de vida diária dos estudantes de educação especial}

A professora atende de maneira mais próxima um dos alunos. Ela o acompanha desde o carro dos pais, na entrada da escola, até a sala de aula. Nesse deslocamento, a professora carrega a própria mochila e a do aluno (Figura 11), segundo ela, para proteger o aluno, que caminha lentamente. Ela também o acompanha ao banheiro e durante o recreio, quando está sem os bolsistas.

\subsubsection{Comunicação com os professores}

Entre uma aula e outra ou nos intervalos, a professora de Educação Especial sempre se comunica com os professores das diferentes matérias (Figura 12). As conversas são rápidas, não ultrapassam cinco minutos. Durante esse tempo, a professora da Educação Especial comunica aos outros professores como irá fazer a flexibilização do conteúdo para os seus alunos.

\subsubsection{Orientação aos bolsistas}

A orientação aos bolsistas ocorre durante as aulas, não havendo programação prévia. Assim que a professora chega, ela diz aos bolsistas o que fazer e qual aluno acompanhar. A professora pede aos bolsistas para irem buscar materiais e impressões. Durante os intervalos, ou quando a professora precisa se ausentar da sala, a comunicação entre a professora e os seus bolsistas acontece via mensagem de texto. Os bolsistas passam para a professora informações dos alunos através de um aplicativo de mensagem de texto.

\subsubsection{Avaliação da carga de trabalho}

A carga de trabalho percebida após a reunião de professores resultou em 56,7 pontos, de um total possível de 100 pontos. Ela concentrou-se principalmente em exigência mental e esforço, (Figura 14, Apêndice). Não foi atribuída importância à exigência física nessa avaliação. A carga de trabalho percebida após uma tarde de trabalho, que compreendeu principalmente acompanhamento dos estudantes em sala de aula, resultou em 72 pontos, 15,3 pontos a mais que a carga de trabalho percebida durante a manhã. Durante a tarde a carga de trabalho concentrou-se em exigência mental, nível de frustração e esforço, com menor importância atribuída às dimensões exigência temporal, desempenho e exigência física (Figura 15, Apêndice). 


\section{$16^{\circ}$ \\ ERGODESIGN USIHC CINAHPA}

\subsubsection{Deslocamentos}

Durante uma tarde (13h30min - 16h55min), a professora andou aproximadamente $3 \mathrm{~km}$ dentro da escola. Ela relata: "As coisas são longe nessa escola. Acho que já subi essa escada umas 20 vezes hoje." Os espaços utilizados pela professora estão em diferentes andares (Figura 16, Apêndice); além de andar grandes distâncias, ela sobe e desce escadas e rampas com frequência para buscar materiais, impressões e trocar de sala.

O percurso marcado em preto na Figura 16 é feito quando a professora acompanha o aluno da entrada da escola até a sala do $9^{\circ}$ ano, percorrendo aproximadamente $120 \mathrm{~m}$; ela faz esse trajeto no início e no final da aula. O percurso marcado em azul é feito para buscar materiais na sala da Educação Especial ( $2^{\circ}$ andar). A distância entre esta sala e a sala do $9^{\circ}$ ano é $100 \mathrm{~m}$; a professora faz esse caminho em média quatro vezes ao dia. $\mathrm{O}$ percurso marcado em vermelho $(180 \mathrm{~m}$ de distância) é feito para buscar materiais no Laboratório, ao menos duas vezes ao dia; em nenhuma das vezes observadas, a professora solicitou que algum bolsista fizesse este percurso no lugar dela. Para as impressões em preto e branco (ponto 2 ao 5 da Figura 16), o deslocamento é de $20 \mathrm{~m}$, mas na maioria das vezes um bolsista faz essa atividade.
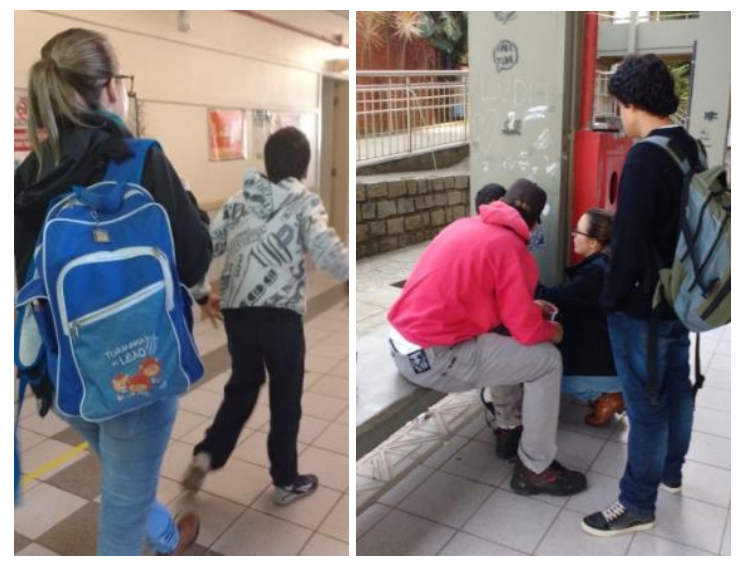

Figura 11: Professora acompanhando o estudante da Educação Especial do carro dos pais até a sala de aula (esquerda) e atendendo o estudante no intervalo (direita). Fonte: autoras, 2016. $16^{\circ}$ Ergodesign - Congresso Internacional de Ergonomia e Usabilidade de Interfaces Humano Tecnológica: Produto, Informações Ambientes Construídos e Transporte

$16^{\circ}$ USIHC - Congresso Internacional de Ergonomia e Usabilidade de Interfaces Humano Computador

CINAHPA | 2017 - Congresso Internacional de Ambientes Hipermídia para Aprendizagem.

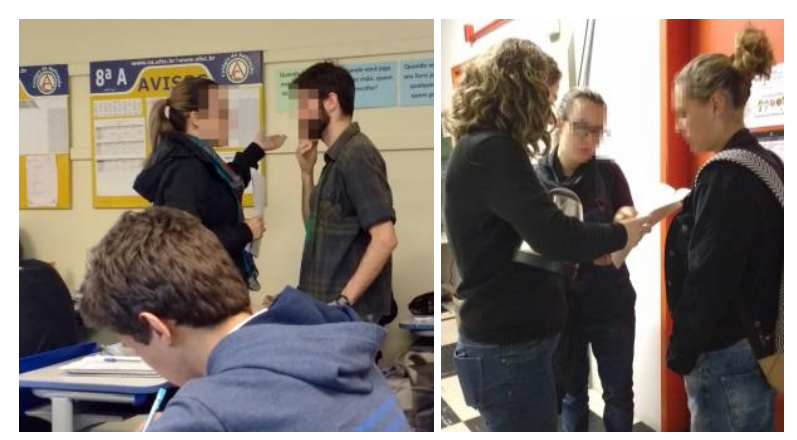

Figura 12: Professora com o professor de História na sala de aula do $9^{\circ}$ ano (esquerda) e com a professora de inglês e outra professora da Educação Especial no corredor do $2^{\circ}$ andar (direita). Fonte: autoras, 2016.

\subsubsection{Distribuição das atividades no tempo de trabalho}

As atividades realizadas pela professora durante uma tarde de trabalho (13h30min a $17 \mathrm{~h} 30 \mathrm{~min})$ na sala de aula regular estão representadas no Gráfico 1. Ela passa a maior parte do seu tempo no atendimento aos alunos da educação especial; em média 95 minutos em atividades diretamente ligadas ao atendimento deles (atendimento em sala, recreio e deslocamento). A orientação aos alunos de Iniciação Científica também ocupa bastante tempo da professora, em média 58 minutos. A professora tem 30 minutos de intervalo (das $16 \mathrm{~h}$ às 16h30min). Nos dois dias acompanhados, a professora passou o seu intervalo na sala da Educação Especial e os alunos são acompanhados pelos bolsistas. Os deslocamentos feitos ao longo da tarde para buscar materiais, recursos e impressões coloridas somam 28 minutos.

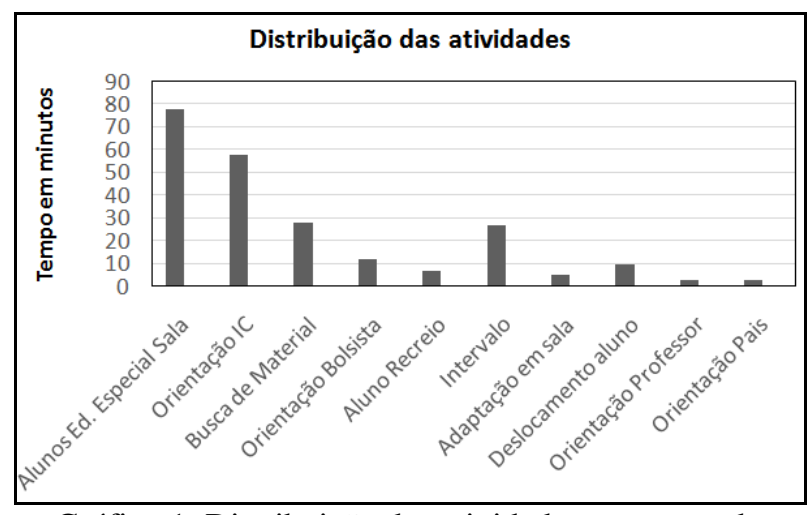

Gráfico 1: Distribuição das atividades no tempo de trabalho da professora. Fonte: autoras, 2016. 


\section{$16^{\circ}$ \\ ERGODESIGN USIHC CINAHPA}

A orientação aos bolsistas ocorre durante a aula e simultaneamente ao atendimento dos alunos e ocupa cerca de 12 minutos. Durante a aula e o atendimento do aluno, a professora passa cerca de 5 minutos fazendo ajustes nas atividades no próprio notebook. A orientação aos pais dos alunos acontece geralmente no início e no final da aula. A orientação aos professores acontece geralmente nos intervalos das aulas e nos corredores da escola. Ambas acontecem de forma verbal e rápida e ocupam cada uma 5 minutos da tarde de trabalho. Se considerarmos que a orientação aos bolsistas (12min) e a adaptação de materiais (5min) acontecem de forma simultânea ao acompanhamento dos alunos, podemos dizer que em vez de 95 minutos de atendimento, a professora atende exclusivamente aos alunos de educação especial durante 78 minutos. Considerando esse total de 78 minutos dedicados exclusivamente aos alunos, observa-se que o tempo utilizado para buscar materiais (28 $\mathrm{min}$ ) representa um terço do tempo dedicado aos alunos da educação especial.

\section{Conclusão}

A ação ergonômica tem como principal finalidade transformar o trabalho (GUÉRIN et al., 2001).

Portanto, a conclusão deste trabalho compreende a apresentação do diagnóstico e das recomendações ergonômicas, tendo em vista a demanda.

A co-docência entre professores das disciplinas e professores da educação especial é uma prática recente no Colégio, estabelecida na Proposta Pedagógica de Inclusão Educacional, de 2014. A comunicação entre a professora de educação especial e os professores das disciplinas ocorre em momentos informais, durante as aulas, nos corredores, ou por e-mail. Sugere-se, em relação a esse problema: estabelecer um momento formal, por semana, para planejamento das atividades de professores da educação especial e professores das demais disciplinas conjuntamente. Esse encontro pode ter duração de uma a duas horas, de forma a não sobrecarregar os envolvidos.

Os materiais para os estudantes da educação especial são adaptados, com frequência, durante as aulas, gerando interrupções no atendimento a esses estudantes e na própria aula. Portanto, pode-se criar um repositório (de preferência online) para os materiais "originais" das diferentes disciplinas e os adaptados para estudantes da educação especial. Dessa forma, os professores das disciplinas podem disponibilizar, com antecedência, os materiais que produziram, permitindo aos professores da educação especial acessar e trabalhar nas adaptações antes das aulas. Além disso, esse repositório pode evitar retrabalho por parte da equipe de professores da educação especial e estimular o compartilhamento do conhecimento.

A professora orienta os bolsistas na própria sala de aula ou por mensagens de texto (celular) durante a aula. Quando precisa conversar com o bolsista sobre o comportamento do aluno, sai da sala e conversam no corredor. Conforme as situações observadas, percebe-se que esta falta de comunicação gera improvisos na educação dos alunos especiais, visto que a professora em algumas situações precisa sair da sala de aula e não consegue deixar nenhuma orientação aos bolsistas. Para solucionar esse problema, sugere-se que a professora e os bolsistas comecem seu turno vespertino a partir das $13 \mathrm{~h}, 30$ minutos antes do início da aula. Nesse período, a professora pode orientar os bolsistas quanto às atividades da tarde, solicitar que busquem materiais, etc.

Foram observadas situações nas quais o número de alunos é maior do que a capacidade da sala do AEE, em função do mobiliário atual. Por isso, propõem-se algumas modificações no layout (Figura 13): o novo layout da sala do AEE tem uma mesa retrátil, mais cadeiras, redução de profundidade dos móveis para tornar a sala de aula acessível e ter a possibilidade de realização de aulas em conjunto, com mais professores e alunos. Ainda em relação ao espaço físico, percebeu-se que a professora desloca-se para buscar materiais, impressões e durante as trocas de salas com os estudantes várias vezes durante o dia. As salas utilizadas pela professora estão distantes umas das outras, fazendo com que esses deslocamentos gerem uma grande distância percorrida durante cada período de trabalho. Dessa forma, recomendase que a professora repasse a função de buscar materiais aos bolsistas, para que possa permanecer

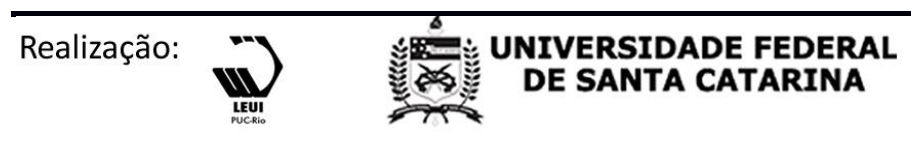


com os alunos em sala de aula.

A professora precisa de autorização de diferentes profissionais para realizar atividades como o empréstimo de Tecnologias Assistivas e recursos eletrônicos por um período maior que um turno. $\mathrm{O}$ laboratório onde estão esses recursos localiza-se no prédio anexo (a 180m da sala de aula). Nesse mesmo prédio está a única impressora colorida que a professora utiliza. Para diminuir esse problema, sugere-se: permitir que as professoras de Educação Especial possam locar os recursos por um período maior de tempo sem precisar de autorização prévia; e disponibilizar uma impressora colorida na sala de Educação Especial, que fica mais próxima à sala de aula do $9^{\circ}$ ano e à sala do AEE, além de ser utilizada com frequência pela professora.

Considera-se uma limitação deste trabalho a quantidade de visitas para acompanhamento da professora realizando suas atividades. Devido ao limite de tempo para realização da análise e das restrições de disponibilidade da professora para receber as pesquisadoras, foi possível observá-la durante dois dias. A pesquisa acompanhou apenas uma professora de educação especial, portanto seus resultados são aplicáveis a este caso específico.

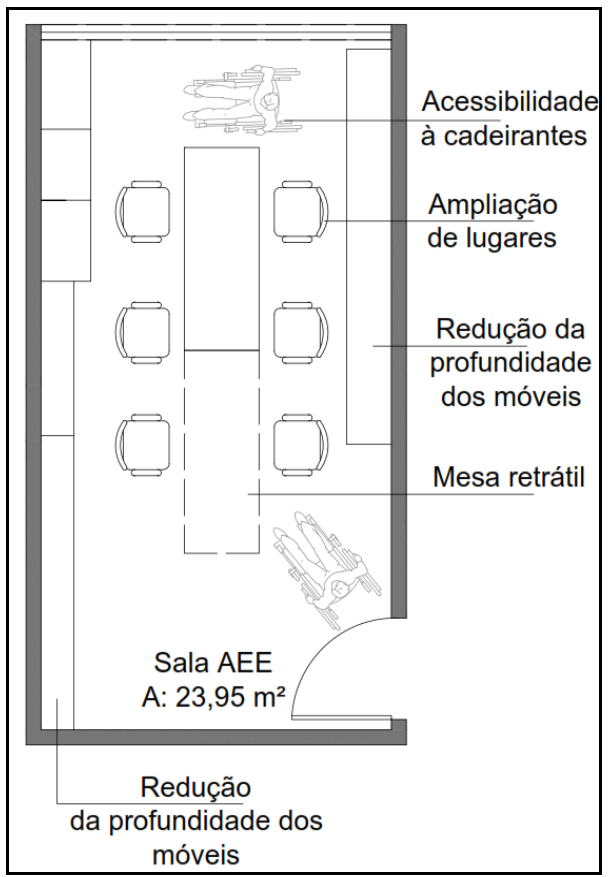

Figura 13: Proposição de layout da sala de Atendimento Educacional Especializado. Fonte: autoras, 2016. $16^{\circ}$ Ergodesign - Congresso Internacional de Ergonomia e Usabilidade de Interfaces Humano Tecnológica: Produto, Informações Ambientes Construídos e Transporte

$16^{\circ}$ USIHC - Congresso Internacional de Ergonomia e Usabilidade de Interfaces Humano Computador

CINAHPA | 2017 - Congresso Internacional de Ambientes Hipermídia para Aprendizagem.

\section{BIBLIOGRAFIA}

ALVES, W. F. A invisibilidade do trabalho real: o trabalho docente e as contribuições da ergonomia da atividade. 37a Reunião Nacional da ANPEd, outubro de 2015, UFSC - Florianópolis.

BRASIL. LDB - Lei no 9394/96. Estabelece as diretrizes e bases da Educação Nacional. Brasília: MEC, 1996.

FERREIRA, L. L. Sobre a Análise Ergonômica do Trabalho ou AET. Revista Brasileira de Saúde Ocupacional, [S. 1.], v. 40, n. 131, p.8-11, jun. 2015.

GUÉRIN, F. et al. Compreender o trabalho para transformá-lo: a prática da ergonomia. São Paulo: Edgard Blucher, 2001.

NASA Ames Research Center. NASA Task Load Index: paper and pencil package, 1986. Disponível em:

https://humansystems.arc.nasa.gov/groups/tlx/tlxpa perpencil.php.
Realização:
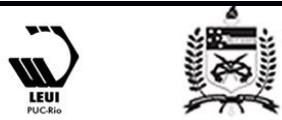


\section{$16^{\circ}$ \\ ERGODESIGN \\ USIHC CINAHPA}

$16^{\circ}$ Ergodesign - Congresso Internacional de Ergonomia e Usabilidade de Interfaces Humano Tecnológica: Produto, Informações Ambientes Construídos e Transporte

$16^{\circ}$ USIHC - Congresso Internacional de Ergonomia e Usabilidade de Interfaces Humano Computador

CINAHPA | 2017 - Congresso Internacional de Ambientes Hipermídia para Aprendizagem.

\section{APÊNDICE}

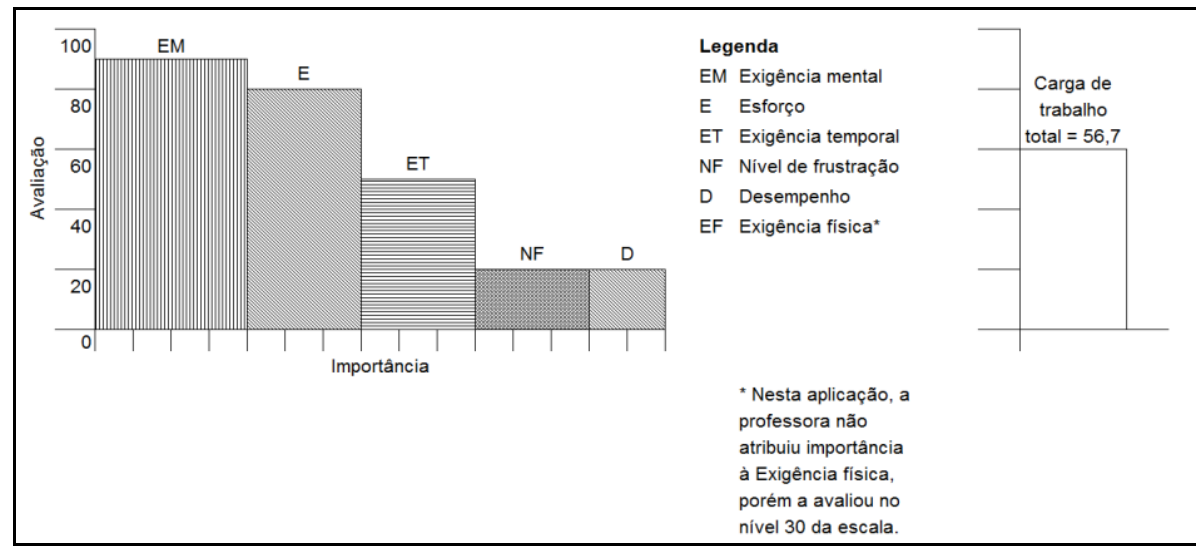

Figura 14: Resultado da avaliação da carga de trabalho, período da manhã, reunião de professores do $9^{\circ}$ ano.

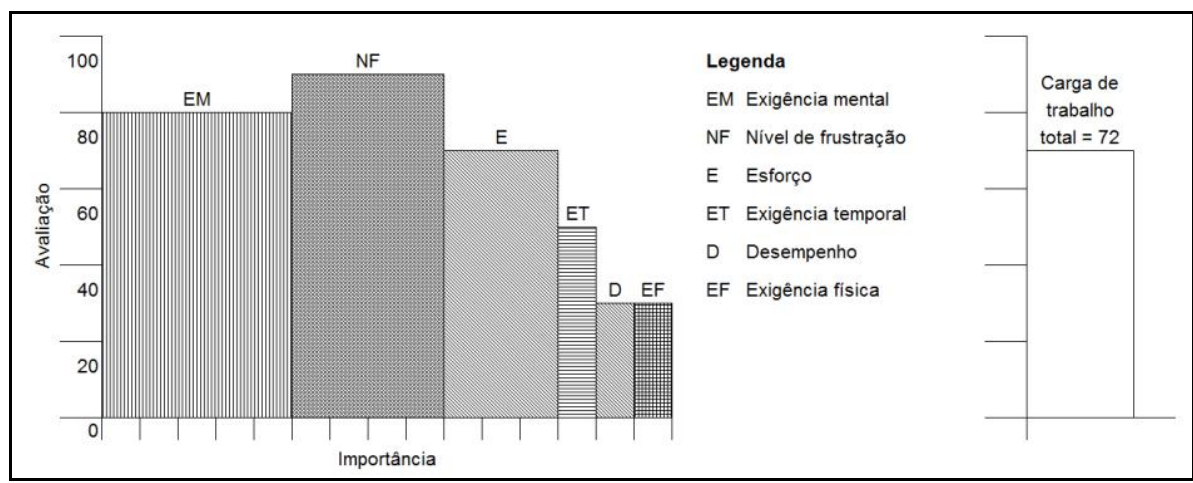

Figura 15: Resultado da avaliação da carga de trabalho, período da tarde, acompanhamento do aluno em sala de aula.

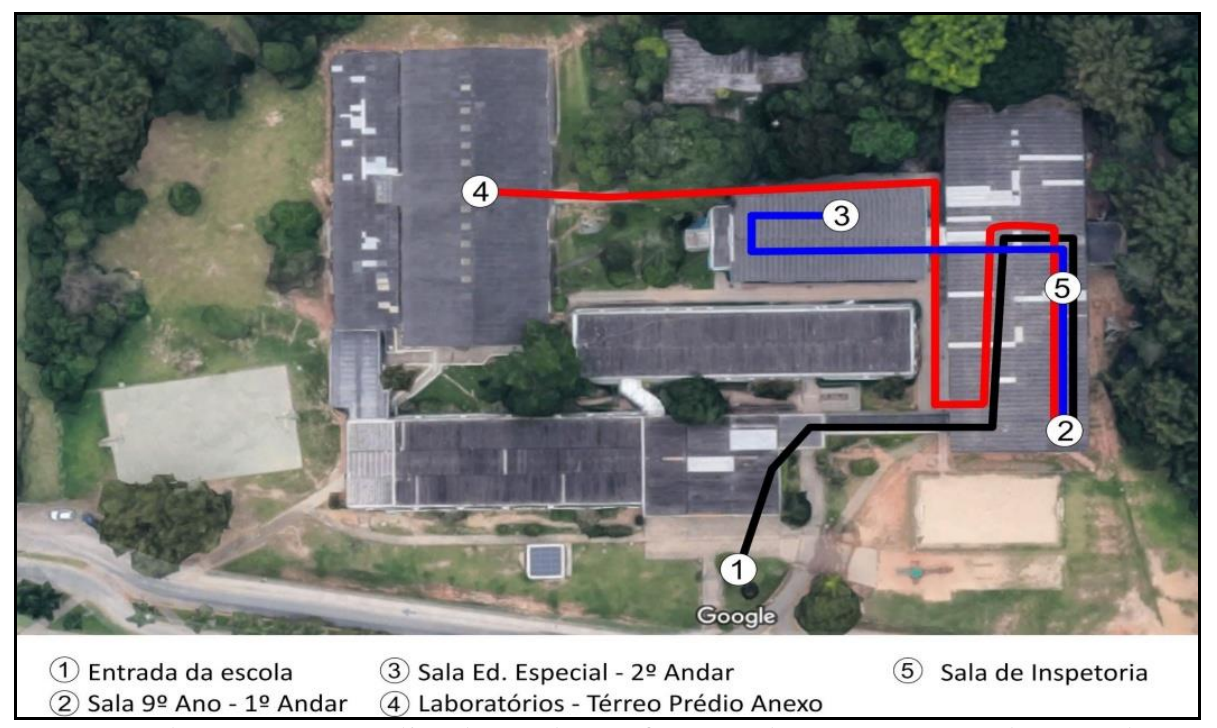

Figura 16: Deslocamentos realizados pela professora durante uma tarde na aula regular. 